\title{
A new type of Antarctic carbonaceous chondrite with CI affinities
}

Three Antarctic meteorites, Yamato-82162, Yamato-86720, and Belgica-7904, are unusual carbonaceous chondrites having characteristics of both CI (Carbonaceous Ivuna-type) and CM (Carbonaceous Mighei-type) chondrite groups, and an international research consortium has carried out studies on these three chondrites. Many striking and fruitful results have been obtained by the consortium studies. (1) Rare or unique minerals, such as sodian talc, $\mathrm{FeO}$-bearing periclase, an unknown $\mathrm{Fe}-\mathrm{Ca}-\mathrm{S}-\mathrm{O}$ mineral, eskolaite, and schreibersite, were found in the unusual carbonaceous chondrites. (2) Phyllosilicate veins formed first in the meteorites, which suggests that hydration took place in the parent body. (3) In spite of the phyllosilicate veins, detailed mineralogy of the altered chondrules and clasts and oxygen isotopic data reveal that most of the phyllosilicates in the chondrules and clasts were produced from anhydrous precursors in the solar nebula. (4) At the final stage of chondrite formation, the three chondrites underwent intense heating after the hydrous alteration in or on their parent body. (5) Mineralogical, chemical, and isotopic data indicate that the three chondrites have some characteristics of both $\mathrm{CI}$ and $C M$ chondrite groups, and the genetical relationships between the two groups have been brought to light.

\section{Introduction}

Between 1969 and 1990 A.D.. Japanese exploration parties have collected many meteorites. numbered up to 8.500, from Antarctica. The large number of meteorites includes many new types that are not known among non-Antarctic meteorites. Three unusual carbonaceous chondrites, Yamato-82162, Yamato-86720, and Belgica-7904, are among the new types; they show some features that are characteristic of both $\mathrm{CI}$ and $\mathrm{CM}$ chondrites. Among all the meteorites, the $\mathrm{CI}$ chondrites have the most primitive compositions, which are similar to the Sun except for the gaseous components. Detailed studies of the new Antarctic carbonaceous chondrites may give us new insights into the processes of formation of the primitive meteorites, processes that took place in the solar nebula and in primitive meteorite parent bodies.
The B-7904 chondrite was first classified as a C2 or CM chondrite because of the presence of chondrules and phyllosilicatelike minerals (Meteorite News, 1982), but later it was grouped as a C3 because of its low water content (Haramura and others, 1983) (table 1). Therefore, B-7904 may have been originally a CM that later was heated and lost its water (Kojima and others, 1984). Y-82162 and Y-86720 were considered to be $\mathrm{Cl}$ or $\mathrm{CI}$ because of the absence or scarcity of chondrules (Yanai and Kojima, 1987; Kojima and Yanai, 1987), in spite of their low water contents (table 1). Surprisingly, the oxygen isotopic compositions of all three chondrites (fig. 1) are similar to those of non-Antarctic $\mathrm{Cl}$ chondrites (Mayeda and others, 1987; Clayton and Mayeda, 1989). Therefore, in order to study the three carbonaceous chondrites, a research consortium was organized in 1987 with the title "Antarctic Carbonaceous Chondrites With CI Affinities, B-7904, Y-86720, and Y-82162" (Leader: Y. Ikeda). Since then, these meteorites have been studied by many Japanese, American, and European meteorite researchers using broad bases including mineralogy, petrology, traceelement and isotope geochemistry, and organic chemistry, for example. Although the results of the consortium study are not yet fully published, we report here the summary and new knowledge on these new carbonaceous chondrites.

\section{Petrography}

The three carbonaceous chondrites are breccias and consist mainly of the fine-grained matrix, many kinds of clasts (inclusions, aggregates, or clusters), and isolated minerals. They also contain chondrules, except for $\mathrm{Y}-82162$, which includes anhydrous chondritic fragments instead. The petrological and mineralogical features of the three chondrites are summarized in table 1.

\section{$\mathbf{Y}-\mathbf{8 2 1 6 2}$}

This chondrite is a fine-grained, black, massive aggregate that shows a breccia-in-breccia texture. Chondrules are not found, and the matrix is the main constituent. Clasts are mostly smaller than 500 micrometers across and are set in the fine-grained matrix. They are classified on the basis of major minerals and (or) texture into several types of clasts, such as phyllosilicate, matrix-like, carbonate, and unusual clasts including $\mathrm{FeO}$-bearing periclase. In addition to these clasts, Y-82162 includes anhydrous chondritic fragments that are similar to ordinary chondrites. Isolated minerals are sulfides, oxides, and dehydrated phyllosilicates. Pyrrhotite laths are scattered in the matrix. The matrix consists mainly of fine-grained dehydrated pnyllosilicates and minor variable amounts of opaque minerals.

\section{Y-86720}

This chondrite includes completely altered chondrules in addition to a few types of clasts, isolated minerals, and matrix. The altered chondrules show pseudomorphs of porphyritic olivine chondrules, 
although original anhydrous minerals have been altered completely to aggregates of dehydrated phyllosilicates. Clasts are aggregates consisting mainly of dehydrated phyllosilicates and (or) opaque minerals. Isolated minerals are sulfides, oxides, and dehydrated phyllosilicates, and troilite laths are scattered in the matrix. The matrix consists mainly of fine-grained dehydrated phyllosilicates and variable amounts of opaque minerals.

\section{B-7904}

This chondrite includes many partially altered chondrules that have undergone hydrous alteration in various degrees. Large chondrules commonly show a core and mantle structure. The core is an unaltered part of the original chondrule, and the mantle, 50-400 micrometers thick, is an altered part consisting mainly of dehydrated phyllosilicates and relic olivine. Clasts are aggregates made up mainly of dehydrated phyllosilicates and variable amounts of opaque minerals. Isolated minerals include olivine, sulfides, and oxides, and the matrix is a fine-grained aggregate of dehydrated phyllosilicates and variable amounts of opaque minerals.

\section{Bulk chemistry}

In figure 2, atomic abundances of the three Antarctic carbonaceous chondrites, normalized to $\mathrm{CI}$ chondrite, are plotted against the ap- proximate order of decreasing 50 percent nebular condensation temperatures, and they are compared with those of $\mathrm{CI}$ and $\mathrm{CM}$ chondrites as well.

Y-82162 has refractory element abundances close to those of $\mathrm{Cl}$. Abundances of $\mathrm{Al}, \mathrm{Sc}, \mathrm{Ca}$, and rare-earth elements (REE) in the chondrite are similar to $\mathrm{CI}$ chondrites (fig. 2). It appears to have a normal CI mean REE abundance pattern, but precise analyses of REE indicate that the chondrite is slightly enriched in heavy REE (Yamamoto and Nakamura. 1990). This enrichment normally is found in at kind of high-temperature inclusion from $\mathrm{C} 2$ and $\mathrm{C} 3$ chondrites but is unusual for $\mathrm{CI}$ chondrites. Abundances of moderately volatile lithophile elements, typically $\mathrm{Cr} . \mathrm{Mn}$, and alkalis, are again consistent with CI. Some of the least mobile elements in this chondrite exhibit trends contradictory to those of $\mathrm{CI}$; the high content of $\mathrm{U}$ (about $1.22 \times \mathrm{CI}$ ) and the low content of $\mathrm{Sb}$ (about $0.8 \times \mathrm{CI}$ ) suggest $\mathrm{CM}$. The depletion of $\mathrm{Au}$ (about $0.6 \times \mathrm{Cl}$ ) indicates neither $\mathrm{CI}$ nor $\mathrm{CM}$. Despite the general resemblance of $\mathrm{CI}$ in abundance patterns for most lithophile, siderophile, and chalcophile elements, the four most volatile elements, $\mathrm{In}, \mathrm{Bi}, \mathrm{Tl}$, and $\mathrm{Cd}$, show extremely different trend, from those of $\mathrm{CI}$. The depletion factors range up to three orders of magnitude from $\mathrm{S}$ to $\mathrm{Cd}$. Such systematic depletions of elements cannot be explained by the weathering that may have occurred within the Antarctic ice sheets (Paul and Lipschutz, 1990).

Both Y-86720 and B-7904 chondrites, in general, show similar elemental abundance patterns (fig. 2) and resemble $\mathrm{CM}$. However, in a strict sense, $\mathrm{Y}-86720$ is intermediate between $\mathrm{CI}$ and $\mathrm{CM}$ for some refractory elements such as $\mathrm{Al}$ and $\mathrm{Sc}$ and is even between $\mathrm{CM}$ and

Table 1. - The petrological and mineralogical features characteristic of non-Antarctic CI, ordinary CM, and the new type of Antarctic carbonaceous chondrite (Yamato-82162, Yamato-86720, and Belgica-7904)

[ $\mathrm{H}_{2} 0$ contents of the new type are $\mathrm{H}_{2} \mathrm{O}(+)$, and the contents in parentheses include $\mathrm{H}_{2} \mathrm{O}(+$ and -$)$ and carbon dioxide. Chondrules in $\mathrm{Y}_{-86720}$ are altered completely to aggregates of phyllosilicates, shown here as $(+) . \mathrm{Al}_{2}, \mathrm{O}_{3}$ contents are alumina of the phyllosilicates in phyllosilicate clasts (Low, Int, and High are 0-6.5, 6.5-13, and 13-26 wt percent, respectively). Unusual clasts consist mainly of Fe0-bearing periclase and carbonate and a minor amount of unknown Fe-Ca-S-O mineral. Anhy.Chond.Frag. and PCP (poorly characterized phases) are anhydrous- chondritic fragments and aggregates of tochilinite and cronstedtite, respectivels. Matrix opaque minerals are Pyr, pyrrhotite: Fer, ferrihydrite; Mt, magnetite; Pen, pentiandite; Awa, awaruite; Tr, troilite; Ta, taenite; and Toc, tochilinite. Matrix phyllosilicates are Sapo, saponite, and Serp, serpentine. In addition, B-7904 includes eskolaite and schreibersite in small amounts. Data sources: Tomeoka (1990 a, b), Ikeda and others (1991), Kimura and Ikeda (unpublished data, 1991)]

\begin{tabular}{|c|c|c|c|c|c|}
\hline & $\mathrm{Cl}$ & $Y-82162$ & $Y-86720$ & $B-7904$ & $\mathrm{CM}$ \\
\hline l="==" & & & 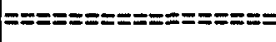 & $==== \pm= \pm==== \pm=$ & \\
\hline $\mathrm{H} 20$ (wt\%) of whole rock & $18-23$ & $8.01(11.95)$ & $4.6(6.1)$ & $2.1(2.6)$ & $4-16$ \\
\hline Chondrules & no & no & $(t)$ & + & $t$ \\
\hline Phvllosilicate Clasts & & L (drabudnotod) & & & 1 \\
\hline A1203 contents & Low & $\begin{array}{c}+ \text { (denydratea) } \\
\text { Low }\end{array}$ & $\begin{array}{l}\text { +(denyorated) } \\
\text { Low, Int, High }\end{array}$ & $\begin{array}{l}\text { f(dehydrated) } \\
\text { Low, Int, High }\end{array}$ & Low, Int,High \\
\hline Mg0-bearing Clasts & no & + & no & no & no \\
\hline Anhy. Chond.Frag. & no & + & no & no & no \\
\hline PCP & no & no & no & no & + \\
\hline Matrix Opaque Minerals & Pyr, Fer, Mt, Pen & Pyr, Mt, Awa, Pen & $\mathrm{Tr}, \mathrm{Ta}, \mathrm{Mt}$ & $\mathrm{Tr}, \mathrm{Ta}, \mathrm{Mt}, \mathrm{Pen}$ & Toc, Mt, Pyr \\
\hline Matrix Phyllosilicates & Sapo,Serp & Dehydrated & Dehydrated & Dehydrated & Serp \\
\hline 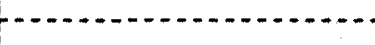 & & & & & \\
\hline Framboidal Magnetites & + & + & no & no & no \\
\hline Veins & Sulfate, Carbonate & Phyllosilicate & & Carbonate & arbon \\
\hline
\end{tabular}




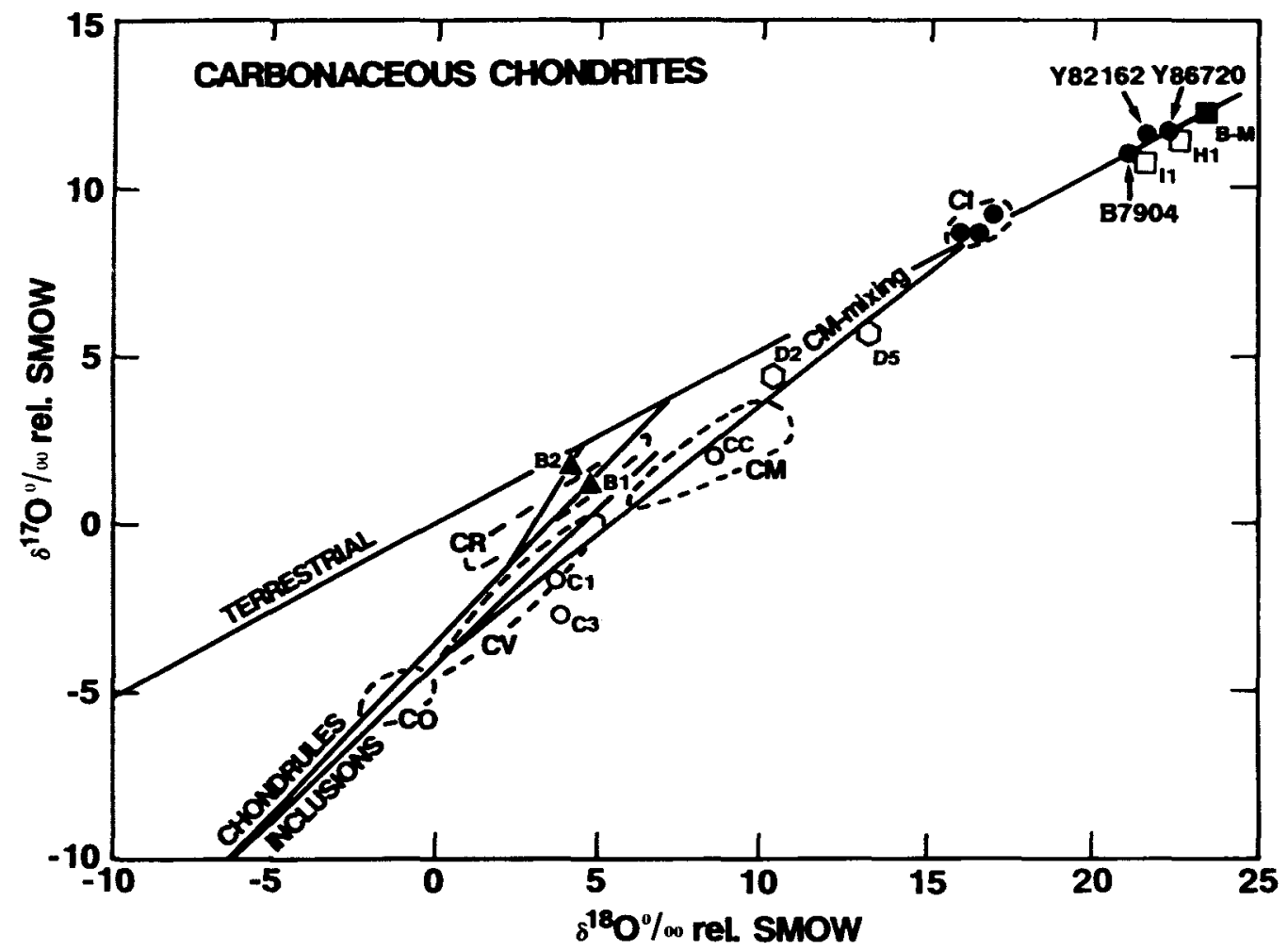

Figure 1.-Oxygen isotopic compositions of whole rocks (Yamato-82162, Yamato-86720, and Belgica-7904), separates from Belgica-7904 (three chondrules, C1, C3, and CC; two phyllosilicate clasts, D2 and D5; two olivine fragments, B1 and B2; and matrix, B-M), and separates from $Y-86720$ (two phyllosilicate clasts, $H 1$ and 11). Terrestrial mass fractionation line (TERRESTRIAL), chondrules-in-carbonaceous-chondrites mixing line (CHONDRULES) with a branch of the chondrule mixing line for Allende barred olivine chondrules (toward B2), inclusion mixing line (INCLUSIONS), and $C M$-chondrite mixing line (CM-mixing) are shown with references of compositional ranges of $C I$, $\mathrm{CM}, \mathrm{CV}, \mathrm{CO}$, and $\mathrm{CR}$ groups. Data and mixing lines are quoted from Clayton and Mayeda (1989), Mayeda and others (1991), Clayton and others (1983), and Clayton and Mayeda (1984). Oxygen isotopic values are given relative to standard mean ocean water (rel. SMOW).

CO (Carbonaceous Ornans-type) for REE. The abundance patterns of moderately volatile elements for B-7904 closely match those of CM, but Y-86720 exhibits occasional depletion of some elements (Au, $\mathrm{Sb}$, and $\mathrm{Zn}$ ) that deviate by far from the $\mathrm{CM}$ trend. Both chondrites, as well as $\mathrm{Y}-82162$, are remarkably depleted in the four most volatile elements (from In to $\mathrm{Cd}$ ), and this is quite unusual for $\mathrm{CM}$, even as it is for other types of normal carbonaceous chondrites. This remarkable depletion of labile element patterns is considered to have been produced by heating after the formation of the three chondrites (Pau) and Lipschutz, 1990). Despite the Cl-like oxygen isotopic compositions for B-7904 and Y-86720 chondrites, the compositional data reported above support a CM classification for both chondrites. However, they may have experienced thermal metamorphism in their parent body, which is responsible for volatile losses.

\section{Hydration and phyllosilicates}

Phyllosilicates, which are now dehydrated (dehydration will be discussed in the following section), are major minerals in the three chondrites, although the degree of hydration differs among the three. Most olivines in B-7904 are almost unaltered, whereas all olivines in
$\mathrm{Y}-86720$ and $\mathrm{Y}-82162$ have been altered to phyllosilicates. In B-7904, chondrules show various degrees of aqueous alteration; the thickness of the phyllosilicate mantle differs among large chondrules, and the mesostases of chondrule cores are altered for some chondrules and unaltered for others. Phyllosilicates in Y-82162 are smectite (saponite), sodian talc, serpentine, and (or) chlorite (Tomeoka and others, 1989a; Zolensky and others, 1989a; Akai, 1990; Ikeda, 1990), and those in Y-86720 and B-7904 are serpentine, smectite, and (or) chlorite (Tomeoka and others, 1989b; Tomeoka, 1990a; Zolensky, 1989b; Akai, 1990). Phyllosilicates differ in kind and chemical composition among the altered chondrules, phyllosilicate clasts, and matrix. For example, many phyllosilicate clasts in Y-82162 consist mainly of sodian talc, but some clasts consist mainly of chlorite (Ikeda, 1990). The $\mathrm{Al}_{2} \mathrm{O}_{3}$ contents of the phyllosilicates in the phyllosilicate clasts and chondrules vary; those in Y-82162 are low ( $<6.5$ wt percent), but those for $Y-86720$ and B-7904 range up to 26 wt percent. In partially altered chondrules of B-7904, the phyllosilicates that have high $\mathrm{Al}_{2} \mathrm{O}_{3}$ contents $(>13$ wt percent) were formed by replacing anorthite, and those that have low $\mathrm{Al}_{2} \mathrm{O}_{3}$ contents ( $<6.5$ wt percent) were formed by replacing enstatite and diopside (Ikeda and others, 1991). On the other hand, phyllosilicates in the matrices of all three chondrites are relatively homogeneous in $\mathrm{Al}_{2} \mathrm{O}_{3}$ content, as they range from 1.5 to $3.0 \mathrm{wt}$ percent. 


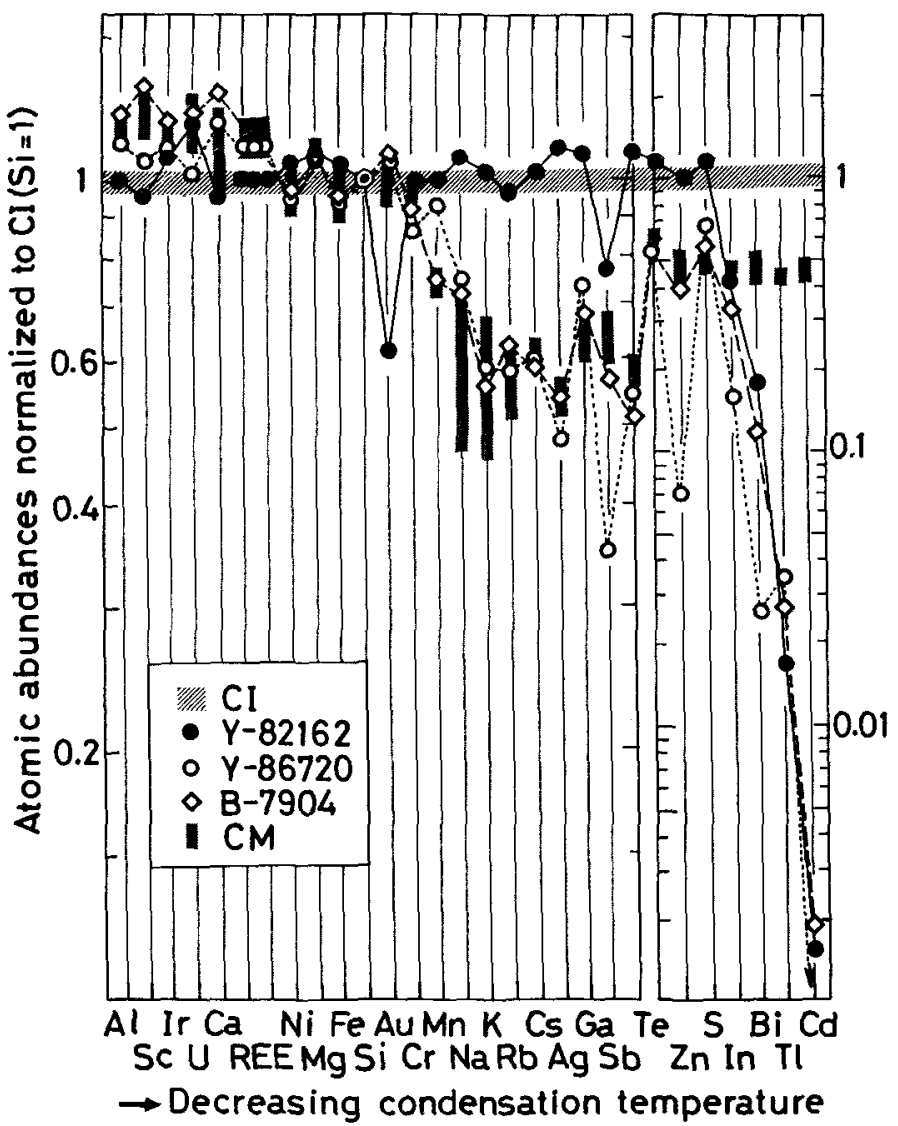

Figure 2.-Atomic abundances, normalized to $\mathrm{CI}$ chondrite $(S i=1)$, of Antarctic carbonaceous chondrites, $Y-82162, Y-86720$, and $B-7904$, compared with non-Antarctic $C I$ and $C M$ chondrites. The CI-normalized values on the left ordinate are for $A l$ to $T e$, and those on the right ordinate are for Te to Cd. Elements are plotted in approximate order of decreasing 50 percent nebular condensation temperatures. Data of Antarctic meteorites are from Paul and Lipschutz (1990), Kallemeyn (1988), and Yamamoto and Nakamura (1990), and data of $C I$ and $C M$ chondrites are from Anders and Grevesse (1989) and Kallemeyn and Wasson (1981).

These lines of evidence indicate that $\mathrm{Y}-82162$ is rather similar to $\mathrm{CI}$ chondrites, and Y-86720 and B-7904 are similar to CM chondrites (table 1).

The alteration of non-Antarctic $\mathrm{Cl}$ chondrites generally is thought to have taken place through the reaction of anhydrous minerals with aqueous solutions in a parent body (Du Fresne and Anders, 1962; Bunch and Chang, 1980), and the presence of framboidal magnetites and sulfate veins provides evidence that aqueous solutions were involved in the alteration (Kerridge and others, 1979; Richardson, 1978). Framboidal magnetites occur in matrix-like clasts in $Y-82162$, but sulfate veins are absent. Instead, phyllosilicate veins, a few micrometers to several tens of micrometers in width, occur within matrix-like clasts in $Y-82162$, and the veins are cut by clast boundaries (Watanabe and others, 1988; Tomeoka, 1990b). They do not occur in the matrix between clasts and chondrules, which indicates that they were produced in a parent body prior to the final agglomeration of the $\mathrm{Y}-82162$ breccia. This is supported by the idea that the projectiles responsible for the regolith gardening were anhydrous chondritic fragments that never underwent alteration in Y-82162 (Ikeda, 1991). Although non-Antarctic CI chondrites are considered to have gone through multistage hydrous alteration, Y-82162 seems to have escaped from late-stage hydration because of the absence of sulfate veins (Tomeoka and others, 1989a).

Involvement of aqueous solutions in the formation of the phyllosilicates may be reasonable for the clasts and matrix of $\mathrm{Y}-82162$. However, partially altered chondrules in B -7904 may not have been produced by reaction with liquid water. In the partially altered chondrules of B-7904, most olivine was not altered, whereas pyroxene and plagioclase were more or less altered to phyllosilicates. This characteristic alteration is explained fully by the idea that the hydration of the chondrules was caused by reactions with a nebular gas (Ikeda and others, 1991); thermodynamic calculation indicates that pyroxene and plagioclase react with $\mathrm{H}_{2} \mathrm{O}$ vapor to produce talc-rich phyllosilicates at temperatures higher than those required for the reaction of olivine to produce serpentine-rich phyllosilicates. Therefore, hydration to produce the phyllosilicates of partially altered chondrules in B-7904 should have taken place at temperatures higher than those that cause the reactions of olivine in the nebula.

\section{Heating and dehydration}

All of the phyllosilicates in $\mathrm{Y}-82162, \mathrm{Y}-86720$, and $\mathrm{B}-7904$ are dehydrated, which suggests that the chondrites were heated after the formation of the phyllosilicates. Transmission electron microscopy revealed that phyllosilicates in the three chondrites were decomposed and formed submicroscopic olivine grains (Akai, 1988; Tomeoka and others, $1989 \mathrm{a}, \mathrm{b}$ ). The dehydrated phyllosilicates in the matrices of Y-86720 and B-7904 seem to have lost the phyllosilicate crystal structures completely (Akai, 1990), although some phyllosilicate structures remain in Y-82162 (Tomeoka and others, 1989a).

The absence of poorly characterized phases (PCP) in B-7904 is explained by the idea that PCP transformed to troilite-metal aggregates by heating in a reduced condition (Tomeoka, 1990a). The difference in the opaque mineralogy of the matrix between nonAntarctic carbonaceous chondrites and the three Antarctic chondrites (table 1) also is explained by the same idea as PCP (Kojima and others, 1984: Tomeoka, 1990a). An alternative idea is that the troilite-metal aggregates and matrices in $\mathrm{Y}-82162, \mathrm{Y}-86720$, and B-7904 were produced originally under reduced conditions and that the three Antarctic chondrites were precursors of non-Antarctic $\mathrm{Cl}$ or CM chondrites (Zolensky and others, 1989a, b).

When the labile element abundances of heated Murchison chondrite are compared with those of $\mathrm{Y}-86720$ and B-7904, the temperatures of the heating events seem to be higher than $600^{\circ} \mathrm{C}$ (Paul and Lipschutz, 1989). Akai (1988, 1990) also has carried out heating experiments by using a terrestrial saponite and a Murchison serpentine, and he concluded that the mineralogical characteristics of the dehydrated phyllosilicates in Y-82162 and Y-86720 are similar to those observed in the samples heated in air for an hour at a temperature of about $800^{\circ} \mathrm{C}$.

\section{Oxygen isotopic composition and our scenario}

Oxygen isotopic compositions of the three Antarctic chondrites, as well as non-Antarctic CI chondrites, are plotted near the terrestrial mass fractionation line (fig. 1). The plot seems to indicate that the three chondrites have an intimate genetical relationship to nonAntarctic CI chondrites. In order to clarify the genetical relationship among chondrules, clasts, and matrix, the oxygen isotopic measure- 
ment and mineralogical investigation have been carried out on several separates from B-7904 and Y-86720 (Mayeda and others, 1991; Ikeda and others, 1991).

As shown in figure 1, the oxygen isotopic compositions of partially altered chondrules and phyllosilicate clasts from B-7904 are largely different from that of the B-7904 matrix. On the other hand, the oxygen isotopic compositions of phyllosilicate clasts ( $\mathrm{H} 1$ and $\mathrm{I1}$ ) from $Y-86720$ are similar to that of the $Y-86720$ whole rock, which suggests that the dehydrated phyllosilicates of the $\mathrm{HI}$ and $\mathrm{Il}$ clasts are probably similar in oxygen isotopic composition to that of the matrix. This difference may be explained by the following alternatives. One alternative is that $Y-86720$ was subjected to intense aqueous alteration in the parent body, which caused a complete exchange between the phyllosilicate clasts and an aqueous solution, although exchange between the B-7904 phyllosilicate clasts and an aqueous solution in the parent body was incomplete during the hydrous alteration. The other alternative is that, although the $\mathrm{Y}-86720$ phyllosilicate clasts were produced by a hydrous reaction with an aqueous solution at low temperatures in the parent body, the B-7904 phyllosilicate clasts were produced by a hydrous reaction with a nebular gas at relatively high temperatures. We prefer the latter alternative because the hydration of the chondrule mantles of B-7904 seems to have taken place in the nebula, as stated above.

Clayton and Mayeda (1984) proposed a two-stage exchange model in order to explain the differences in the oxygen isotopic compositions between the anhydrous minerals and the hydrous matrix in the Murchison chondrite. This model includes a gas-solid exchange in the nebula and a liquid-matrix exchange in the parent body. However, this model does not include a gas-phyllosilicate exchange process. Our scenario requires that a gas-phyllosilicate exchange took place between the two stages of Clayton and Mayeda's model, as follows. First, a nebular gas mixed with anhydrous chondrules, which changed their oxygen isotopic compositions along the chondrule mixing line (the first stage of Clayton and Mayeda's model). This exchange resulted in the relatively heavier oxygen isotopic compositions of B-7904 olivine fragments, B1 and B2 (fig. 1). When the nebular gas cooled at temperatures probably lower than $500-600 \mathrm{~K}$, phyllosilicates became stable in the nebula. Then, replacement of anhydrous silicates in the chondrules took place and formed phyllosilicate mantles and B-7904 chondrules, C1, C3, and CC. Two clasts, D2 and D5, may have been produced by the complete replacement of chondrules. Next, the partially altered chondrules, clasts, isolated minerals such as troilite (or pyrrhotite) laths, and matrix materials accreted to form a parent body. Further cooling of the nebular gas accumulated $\mathrm{H}_{2} \mathrm{O}$ ice on the parent body. The internal heat of the parent body, caused by decay of radionuclides and (or) impact heat, melted the ice and produced liquid water, which disseminated into the deep interiors of the parent body. This resulted in further alteration of the interiors by the liquid water and by the formation of veins (the second stage of Clayton and Mayeda's model). The impact events that followed excavated the interiors to form regolith breccias such as $\mathrm{Y}-82162, \mathrm{Y}-86720$, and B-7904, where hydration did not take place. Finally, these breccias were heated by impacts or metamorphism and underwent dehydration. If the hydration took place completely within the interior of a parent body, non-Antarctic CI chondrites could have been produced by multistage hydration.

\section{Acknowledgments}

We thank Drs. K. Tomeoka and N. Kimura for their critical reading of the manuscript.

\section{References}

Akai, J., 1988, Incompletely transformed serpentine-type phyllosilicates in the matrix of Antarctic CM chondrites: Geochimica et Cosmochimica Acta, v. 52, p. 1593 1599.

_._. 1990, Mineralogical evidence of heating events in Antarctic carbonaceous chondrites, Y-86720 and Y-82162: Proceedings of the NIPR Symposium on Antarctic Meteorites, no. 3, p. 55-68.

Anders, E., and Grevesse, N., 1989, Abundances of the elements: Meteoritic and solar: Geochimica et Cosmochimica Acta, v. 53, p. 197-214.

Bunch, T.E., and Chang, S., 1980, Carbonaceous chondrites; II, Carbonaceous chondrite phyllosilicates and light element geochemistry as indicators of parent body processes and surface conditions: Geochimica et Cosmochimica Acta, v. 44, p. 1543-1578.

Clayton, R.N., and Mayeda, T.K., 1984, The oxygen isotopic record in Murchison and other carbonaceous chondrites: Earth and Planetary Science Letters, v. 67, p. 151-161.

1989, Oxygen isotope classification of carbonaceous chondrites [abs.]: Lunar and Planetary Science Conference, 20th, Houston, Texas, 1989, Abstracts of papers submitted, p. 169-170.

Clayton, R.N., Onuma, N., Ikeda, Y., Mayeda, T.K., Hutcheon, I.D., Olsen, E.J., and Molini-Velsko, C.A., 1983, Oxygen isotopic compositions of chondrules in Allende and ordinary chondrites, in King, E.A., ed., Chondrules and their origins: Houston, Texas, Lunar and Planetary Institute, p. 37-43.

Du Fresne, E.R., and Anders, E., 1962, On the chemical evolution of the carbonaceous chondrites: Geochimica et Cosmochimica Acta, v, 26, p. $1085-1114$.

Haramura, H., Kushiro, I., and Yanai, K., 1983, Chemical compositions of Antarctic meteorites I, in Nagata, T., ed., Proceedings of the Eighth Symposium on Antarctic Meteorites: Memoirs of National Institute of Polar Research, special issue, no. 30, p. 109-121.

Ikeda, Y., 1990, Mineralogy of clasts in the Y-82162 chondrite (Cl) [abs.]: Symposium on Antarctic Meteorites, 15th, Tokyo, p. 81-82.

-1991, Petrology and mineralogy of the Yamato-82162 chondrite (CI): Proceedings of the NIPR Symposium on Antarctic Meteorites, no. 4, p. 187-225.

Ikeda, Y., Mayeda, T.K., Clayton, N.R., and Prinz, M., 1991, Petrography and oxygen isotopic compositions of separates from the Belgica-7904 and Yamato-86720 carbonaceous chondrites [abs.]: Symposium on Antarctic Meteorites, 16th, Tokyo, p. 82-84.

Kallemeyn, G.W., 1988, Compositional study of carbonaceous chondrites with CI-CM affinities [abs.]: Symposium on Antarctic Meteorites, 13th, Tokyo, p. 132-134.

Kallemeyn, G.W., and Wasson, J.T., 1981, The compositional classification of chondrites; I, The carbonaceous chondrite groups: Geochimica et Cosmochimica Acta, v. 45, p. 1217-1230.

Kerridge, J.F., Mackay, A.L., and Boynton, W.V., 1979, Magnetite in CI carbonaceous meteorites: Origin by aqueous activity on a planetesimal surface: Science, v. 205 , p. 395-397.

Kojima, H., Ikeda, Y., and Yanai, K., 1984, The alteration of chondrules and matrices in new Antarctic carbonaceous chondrites, in Nagata, T., ed., Proceedings of the Ninth Symposium on Antarctic Meteorites: Memoirs of National Institute of Polar Research, special issue, no. 35, p. 184-199.

Kojima, H., and Yanai, K., 1987, Yamato-82162; possible first $\mathrm{Cl}$ carbonaceous chondrite from Antarctica [abs.]: Symposium on Antarctic Meteorites, 12th, Tokyo, p. 15.

Mayeda, T.K., Clayton, R.N., and Ikeda, Y., 1991, Oxygen isotopic studies of carbonaceous chondrite Belgica-7904 [abs.]: Lunat and Planetary Science Conference, 22nd, Houston, Texas, 1991, Abstracts of papers submitted, p. 865-866.

Mayeda, T.K., Clayton, R.N., and Yanai, K., 1987, Oxygen isotopic compositions of several Antarctic meteorites, in Yanai, K., ed., Proceedings of the Eleventh Symposium on Antarctic Meteorites: Memoirs of National Institute of Polar Research, special issue, no. 46, p. $144-150$.

Meteorite News, 1982, Meteorite News: Tokyo, National Institute of Polar Research, v. 1, no. 1, p. 26. 
Paul, R.L., and Lipschutz, M.E., 1989, Labile trace elements in some Antarctic carbonaceous chondrites: Antarctic and non-Antarctic meteorite comparisons: Zeitschrift fur Naturforschung, v. A44, p. $979-987$.

-1990, Consortium study of labile trace elements in some Antarctic carbonaceous chondrites: Antarctic and non-Antarctic meteorite comparisons: Proceedings of the NIPR Symposium on Antarctic Meteorites, no. 3, p. 80-98.

Richardson, S.M., 1978, Vein formation in the $\mathrm{Cl}$ carbonaceous chondrites: Meteoritics, v. 13, p. 141-159.

Tomeoka, K., 1990a, Mineralogy and petrology of Belgica-7904: A new kind of carbonaceous chondrite from Antarctica: Proceedings of the NIPR Symposium on Antarctic Meteorites, no. 3, p. 40-54.

$-1990 \mathrm{~b}$, Phyllosilicate veins in a CI meteorite: Evidence for aqueous alteration on the parent body: Nature, v. 345, p. 138-140.

Tomeoka, K., Kojima, H., and Yanai, K., 1989a, Yamato-82162: A new kind of Cl carbonaceous chondrite found in Antarctica: Proceedings of the NIPR Symposium on Antarctic Meteorites, no. 2, p. 36-54.

-1989b, Yamato-86720: A CM carbonaceous chondrite having experienced extensive aqueous alteration and thermal metamorphism: Proceedings of the NIPR Symposium on Antarctic Meteorites, no. 2, p. $55-74$.

Watanabe, S., Tsuchiyama, A., and Kitamura, M., 1988, A preliminary report of mineralogy of Y-82162 (CI) [abs.]: Symposium on Antarctic Meteorites, 13th, Tokyo, p. 128-129.

Yamamoto, K., and Nakamura, N., 1990, REE characteristics of Yamato-82162 and -86720 meteorites and their inference to classification: Proceedings of the NIPR Symposium on Antarctic Meteorites, no. 3, p. 69-79.

Yanai, K., and Kojima, H., 1987, Preliminary identification of new Antarctic meteorites collected by Japanese party in 1986-87 field season [abs.]: Symposium on Antarctic Meteorites, 12th, Tokyo, p. 3.

Zolensky, M.E., Barrett, R.A., and Prinz, M., 1989a, Petrography, mineralogy and matrix composition of Yamato-82162, a new CI2 chondrite [abs.]: Lunar and Planetary Science Conference, 20th, Houston, Texas, 1989, Abstracts of papers submitted, p. 1253-1254.

1989b, Mineralogy and petrology of Yamato-86720 and Belgica-7904 [abs.]: Symposium on Antarctic Meteorites, 14th, Tokyo, p. $24-26$.



Dr. Yukio Ikeda is a Professor in the Department of Earth Sciences at Ibaraki University. Born in Yokohama, Japan, he graduated with bachelor's, master's, and doctor's degrees in geology from Tokyo University, where he especially studied the petrology of granites. He was a staff member of the Geological Department of Tokyo University from 1971 to 1976 . He transferred to Ibaraki University in 1976 and began studying meteorites. Dr. Ikeda served as a leader of a research consortium on a unique enstatite chondrite (Yamato-691) from 1984 to 1987 and also of another consortium on Antarctic carbonaceous chondrites with CI affinities (Belgica-7904, Yamato86720 , and Yamato-82162) from 1987 to 1990 .

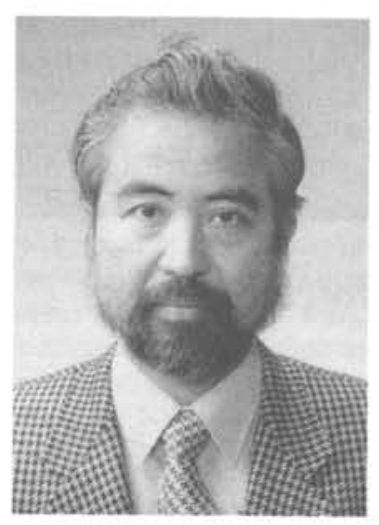

Dr. Noboru Nakamura is an Associate Professor in Geochemistry at the Department of Earth Sciences, Kobe University. Born in Okinawa, Japan, he received his bachelor's and master's degrees in chemistry from Kobe University and a doctoral degree in chemistry from the University of Tokyo. He engaged in trace-element and chronological research on Moon rocks and meteorites in the USA as a Postdoctoral Fellow at the U.S. Geological Survey (Denver) and the Colorado School of Mines from 1975 to 1977 and as a Visiting Associate Professor at Oregon State University (Corvallis) in 1977. He has continued meteorite research and is now a Guest Associate Professor at the National Institute of Polar Research in Tokyo. 